\title{
Importance of silkworm and its wastes to enhance socio- economic status in India
}

\author{
Y.T. Jadhav*, K.N. Tambave, A.D. Chavan and B. Kiran Kumar Babu \\ Department of Agricultural Entomology, Ratnai College of Agriculture, Akluj (M.S.) India
}

\section{ARITCLE INFO \\ Received : 11.02 .2020 \\ Accepted : 27.03.2020}

\section{KEY WORDS :}

Sericulture, Silkworm, Wastes, Socioeconomic, Status

*Corresponding author: Email : rupayogeshjadhav@gmail.com

\begin{abstract}
Mulberry sericulture always been recognized only for commercial production of silk from silkworm. Its quiet true also that at present this sericulture industry is looked as an important source by countries such as China and India to generate global currencies. But several resources regarding mulberry sericulture are still utilized properly. The sericulture waste can be emanated into three kinds i.e., first is beds refuse after silkworm rearing, second mulberry twigs, surplus leaves along with fruits, third waste from coccon reeling such as pupae. Also silkworm excreta and different by products can offer diverse utility either by direct or indirect way in agriculture and rural cottage industries. Hence helping to generate note worthy economic for the sericulture farmers.

How to view point the article : Jadhav, Y.T., Tambave, K.N., Chavan, A.D. and Kiran Kumar Babu, B. (2020). Importance of silkworm and its wastes to enhance socio-economic status in India. Internat. J. Plant Protec., 13(1) : 105-110, DOI : 10.15740/HAS/IJPP/13.1/105-110, Copyright@ 2020: Hind Agri-Horticultural Society.
\end{abstract}

